\section{HLA-DR4 and the spondyloarthropathies}

\section{J D Taurog}

\section{HLA-DR4 may be genetically linked to the spondyloarthropathies}

A nkylosing spondylitis (AS) was first described as a pathological entity in the 1690s by a medical student who found, in a French graveyard, a skeleton in which the ilium, sacrum, and 15 lowest vertebrae were completely fused. ${ }^{1}$ Several similar descriptions were reported during the 18th century. A number of isolated clinical descriptions were reported throughout the 19th century, culminating in the detailed classical descriptions by Bechterew, Strümpell, and Marie in the late 19th century. By the mid-1930s, the classical pathological and radiographic features of AS had been described. Nevertheless, rheumatologists, particularly in America, tended to view AS a variant of rheumatoid arthritis (RA) and referred to the disorder as "rheumatoid spondylitis". ${ }^{2}$ This view was partly based on the similarity between the two diseases of the early inflammatory histology in the peripheral joints and in the cervical spine. ${ }^{3}$ It even prevailed for several decades after the discovery of rheumatoid factor and the observation that patients with "rheumatoid spondylitis" were almost uniformly seronegative. ${ }^{4}$ Other entities with both axial and peripheral arthritis, including Reiter's syndrome and psoriatic arthritis, were often called "rheumatoid variants."

\section{"Ankylosing spondylitis used to be viewed as a variant of rheumatoid arthritis"}

Eventually, careful clinical, pathological, and epidemiological observation led to the concept of the spondyloarthropathies as a group of interrelated rheumatic disorders aetiologically and pathogenetically separate from RA. ${ }^{5}$ This concept was greatly reinforced by the discovery of the association of these disorders with HLA-B27 in the mid-1970s. Further distinction from RA was gained with the discovery that RA is uniquely associated with HLA-DR4, ${ }^{6}$ and the term "rheumatoid variants" largely disappeared from use about 20 years ago.
In this issue of the Annals of the Rheumatic Diseases, Said-Nahal et al report the results of their analysis of HLA haplotypes in 70 French families with two or more cases of spondyloarthropathy. ${ }^{7}$ Although similar studies have been conducted in the past, ${ }^{89}$ this study encompassed a much larger sample size than any previous study, and thus had greater power to detect linkage to alleles other than HLA-B27. Moreover, the present study included analysis of the HLAB27+ unaffected siblings of the patients, a comparison with a large reference sample of French haplotypes, and DNA based typing of HLA-DR alleles. The most interesting finding concerned HLA-DR4. The frequency of this allele was not increased in the patients with spondyloarthropathy, compared with the control population. However, the authors found that the rate of transmission of DR4 - that is, the rate at which a DR4-containing HLA haplotype was inherited from a parent who carried it, rather than the parent's other haplotype-was twice as high in the patients as in their B27+ healthy siblings $(72 \% \vee 36 \%)$, and almost four times higher when only the HLA-B27 negative haplotypes were considered (77\% v $20 \%$, although the $20 \%$ figure is based on only 10 subjects). HLA-DR4 was thus found to be genetically linked to spondyloarthropathy in these families with a corrected $p$ value of approximately 0.01 .

Given this finding, one might have predicted that the linkage to DR4 would preferentially be found in the patients with spondyloarthropathy and predominantly peripheral arthritis. However, the percentage of DR4+ patients was similar, irrespective of whether they had either AS or peripheral arthritis. This is consistent with the authors' conclusion in their original description of 115 multiplex spondyloarthropathy families, that AS appears to be a common clinical end point for all of the spondyloarthropathies, irrespective of the initial or other clinical features. ${ }^{10}$

As with all genetic linkage studies, confirmation of this observation in other groups of spondyloarthropathy families will be important to establish its generality. It will also be of great interest to determine whether the DR4 subtypes of the patients in these families are the same ones that are associated with RA. ${ }^{11}$

This study also identified a statistically significant association with HLA-DR13 in the patients, compared with the control reference population. Weak positive and negative associations with other class II alleles have also been found in several previous studies of the spondyloarthropathies, including a recent large British study of patients with $\mathrm{AS}^{12}$ in which associations with HLA-DRl and HLA-DR8 were reported that were not confirmed by Said-Nahal et al. Some of these class II associations, and their inconsistency from study to study, may reflect a weak linkage disequilibrium between HLA-B27 and HLA-DR alleles that varies in specificity and strength in different populations and subpopulations. The finding in the present study of transmission disequilibrium of HLADR4 even on the B27 negative haplotypes, especially if confirmed, would argue in favour of a true biological effect of DR4, because it bypasses the potential confounding factors of linkage disequilibrium and population stratification.

Considerably more is now known about the molecular and cellular pathogenesis of RA than of any of the spondyloarthropathies. Whereas there is a consensus that the primary seat of pathology in RA is the synovium, in AS there is continued speculation and debate about whether pathogenesis begins in the enthesis, subchondral bone, bone marrow, sites of fibrocartilage, or the synovium. ${ }^{13-15}$ It is sobering that nearly three decades of HLA studies have so far provided relatively little solid information to answer this question. In any case, whatever the pathogenetic differences and similarities of RA and the spondyloarthropathies turn out to be, for the present we can at least be thankful that these conditions share in common a dramatic response to tumour necrosis factor blockade..$^{16-18}$

Ann Rheum Dis 2002;61:193-194

\section{Author's affiliations}

J D Taurog, Division of Rheumatic Diseases, Department of Internal Medicine, University of Texas, Southwestern Medical Center, 5323 Harry Hines Blvd, Dallas, TX 75390-8884, USA

Correspondence to: Professor Taurog; joel.taurog@utsouthwestern.edu

\section{REFERENCES}

1 Bywaters EGL. Historical introduction. In: Moll JMH, ed. Ankylosing spondylitis. Edinburgh: Churchill Livingstone; 1980:1-15.

2 Hench PS. Rheumatism and arthritis: review of the American and English literature for 1940 (eighth rheumatism review). Ann Intern Med 1941;15:1001-108. 
3 Bywaters EGL. Pathological specificity of ankylosing spondylitis: is it yet established? Adv Inflam Res 1985;9:1-13.

4 Grahame W. Is rheumatoid spondylitis a separate entity? Arthritis Rheum 1960;3:88.

5 Moll JM, Haslock I, Macrae IF, Wright V.

Associations between ankylosing spondylitis, psoriatic arthritis, Reiter's disease, the intestinal arthropathies, and Behcet's syndrome. Medicine (Baltimore) 1974;53:343-64.

6 Stastny P. Association of the B-cell alloantigen DRW4 with rheumatoid arthritis. $N$ Engl J Med 1978;298:869-71.

7 Said-Nahal R, Miceli-Richard C, Gautreau C Tamouza R, Borot N, Porcher R, et al. The role of HLA genes in familial spondyloarthropathy: a comprehensive study of 70 multiplex families. Ann Rheum Dis 2002;61:201-6.

8 Hochberg MC, Bias WB, Arnett FC. Family studies in HLA-B27 associated arthritis. Medicine (Baltimore) 1978;57:463-75.

9 Rubin LA, Amos Cl, Wade JA, Martin JR, Bale SJ, Little $\mathrm{AH}$, et al. Investigating the genetic basis for ankylosing spondylitis. Linkage studies with the major histocompatibility complex region. Arthritis Rheum 1994:37:1212-20.

10 Said-Nahal R, Miceli-Richard C, Berthelot JM, Duche A, Dernis-Labous E, Le Blevec G, et al. The familial form of spondylarthropathy: a clinical study of 115 multiplex families. Groupe Francais d'Etude Genetique des Spondylarthropathies. Arthritis Rheum 2000;43: 1356-65.

11 Nepom GT. Major histocompatibility complex-directed susceptibility to rheumatoid arthritis. Adv Immunol 1998;68:315-32.

12 Brown MA, Kennedy LG, Darke C, Gibson K, Pile KD, Shatford JL, et al. The effect of HLA-DR genes on susceptibility to and severity of ankylosing spondylitis. Arthritis Rheum 1998;41:460-5.

13 McGonagle D, Emery P. Enthesitis, osteitis, microbes, biomechanics, and immune reactivity in ankylosing spondylitis. J Rheumatol 2000;27:2302-4.
14 Maksymowych WP. Ankylosing spondylitis - at the interface of bone and cartilage. J Rheumatol 2000;27:2295-301 5 Braun J, Bollow M, Sieper J. Radiologic diagnosis and pathology of the spondyloarthropathies. Rheum Dis Clin North Am 1998;24:697-736.

16 Brandt J, Haibel H, Cornely D, Golder W Gonzalez J, Reddig J, et al. Successful treatment of active ankylosing spondylitis with the anti-tumor necrosis factor alpha monoclonal antibody infliximab. Arthritis monoclonal antibody infliximat

17 Van den Bosch F, Kruithof E, Baeten D, De Keyser $F$, Mielants $H$, Veys EM. Effects of a loading dose regimen of three infusions of chimeric monoclonal antibody to tumour necrosis factor alpha (infliximab) in spondyloarthropathy: an open pilot study. Ann spondyloarthropathy: an open pil
Rheum Dis 2000;59:428-33.

18 Marzo-Ortega H, McGonagle D, O'Conner $P$, Emery P. Efficacy of etanercept in the treatment of the entheseal pathology in resistant spondylarthropathy: a clinical and magnetic resonance imaging study. Arthritis Rheum 2001;44:2112-17. 